\title{
Stimulus Properties of Nicotine, Amphetamine, and Chlordiazepoxide as Positive Features in a Pavlovian Appetitive Discrimination Task in Rats
}

\author{
Matthew I Palmatier*, , Jamie L Wilkinson², Dawn M Metschke² and Rick A Bevins ${ }^{2}$ \\ 'Department of Neuroscience, University of Pittsburgh, Pittsburgh, PA, USA; '2Department of Psychology, University of Nebraska-Lincoln, Lincoln, \\ NE, USA
}

\begin{abstract}
Recent experiments from our laboratory have demonstrated that drug states can signal when environmental cues will be followed by rewarding outcomes (ie Pavlovian conditioning). However, little is known about the generality of this approach and whether it can be used for studying the pharmacological properties of drug states. Accordingly, the present experiments tested the pharmacological specificity of nicotine $(0.4 \mathrm{mg} / \mathrm{kg})$, amphetamine $(\mathrm{Img} / \mathrm{kg}$ ), and chlordiazepoxide (CDP, $5 \mathrm{mg} / \mathrm{kg})$ in this Pavlovian drug discrimination procedure. Following drug administration, presentation of a conditional stimulus (CS) was followed by brief access to sucrose. When saline was administered, the same CS was presented but sucrose was withheld. In substitution tests, rats in each condition received varying doses of all training drugs and caffeine. Anticipatory food seeking developed during the CS on drug sessions but not on saline sessions for all drug features (ie drug state-specific conditional response (CR)). In generalization tests, this CR decreased as a function of decreases in the training dose. Median effective doses $\left(E_{50} \mathrm{~s}\right)$ were calculated for nicotine $(0.054 \mathrm{mg} / \mathrm{kg})$, amphetamine $(0.26 \mathrm{mg} / \mathrm{kg})$, and CDP $(2.48 \mathrm{mg} / \mathrm{kg})$. No compound tested substituted for the CDP training drug. Partial substitution was evident between nicotine and amphetamine; CDP did not substitute for either of these drug features. Caffeine fully substituted for nicotine $\left(E D_{50}=15.45 \mathrm{mg} / \mathrm{kg}\right)$ and amphetamine $\left(E_{50}=3.70 \mathrm{mg} / \mathrm{kg}\right)$, but not for CDP. These results are consistent with the hypothesis that drug states can occasion appetitive Pavlovian CRs in a pharmacologically specific manner.

Neuropsychopharmacology (2005) 30, 731-74I, advance online publication, 8 December 2004; doi: I0.1038/sj.npp. 1300629
\end{abstract}

Keywords: abused drugs; appetitive; drug discrimination; reward learning; generalization; benzodiazepine

\section{INTRODUCTION}

The foundation for our understanding of subjective drug effects comes from human and non-human animal 'drug discrimination' research (see Colpaert, 1999). These models typically require the subject to make a choice, such as pressing one of two different levers (Stolerman and D'Mello, 1981) or placing poker chips into one of two different containers (Perkins et al, 1994), depending on the presence or absence of a drug state. For example, when the pharmacological effects of amphetamine are present, a rat is required to press one lever (eg left) 10 times to receive food reward; pressing the right lever does not result in any programmed outcome (eg Stolerman and D'Mello, 1981). When amphetamine is absent, this contingency is reversed.

*Correspondence: Dr MI Palmatier, Department of Neuroscience, 446 Crawford Hall, University of Pittsburgh, Pittsburgh, PA I5260, USA, Tel: + I 4I2 624 7345, Fax: + I 4126247295 ,

E-mail: mip16@pitt.edu

Received 15 July 2004; revised 5 October 2004; accepted 29 October 2004

Online publication: I November 2004 at http://www.acnp.org/citations/ Npp I $10104040326 /$ default.pdf
As a result of this training, rats consistently choose the lever that corresponds to each drug state, indicating that the pharmacological cues (or lack thereof) 'set the occasion' for the response that will be reinforced (Colpaert et al, 1976; Skinner, 1938).

Performance in operant drug discrimination tends to reflect the pharmacological properties and cellular actions of the training drug (eg Holtzman and Locke, 1988). This specificity allows researchers to explore and categorize the pharmacological properties of psychoactive compounds. For example, microinjections of nicotine into the medial prefrontal cortex and dorsal hippocampus evoke nicotineappropriate responding in rats trained to discriminate nicotine from saline via subcutaneous injections (Miyata et al, 1999; Shoaib and Stolerman, 1996). In contrast, microinjections of nicotine into the nucleus accumbens or the medial habenular nucleus did not result in nicotineappropriate responding. These studies and others (eg Stolerman et al, 2002) have helped to characterize brain areas and neurotransmitter receptor systems that contribute to the nicotine 'drug state'.

Recently, some researchers have been exploring alternative paradigms in which to study the stimulus properties 
of drug states. One such model, sometimes called discriminated taste aversion (Herrera and Velazquez Martinez, 1997; Jaeger and Mucha, 1990; Kautz et al, 1989; Lucki, 1988; Mastropaolo et al, 1989; Revusky et al, 1982), involves pairing a flavor with an aversive outcome, but only under certain physiological circumstances. Similar to operant drug discrimination research, subjects are provided with different contingencies depending on the presence or absence of a drug state. However, the drug state sets the occasion for the pairing of two stimuli: typically access to a novel flavor (eg $0.15 \%$ saccharin solution) followed by an aversive outcome (eg lithium chloride injection). Rats readily learn to avoid the flavor stimulus. However, this avoidance is only evident in the drug state that has signaled occurrence of the aversive outcome (Martin et al, 1990). This discriminated avoidance behavior is also specific to the pharmacological properties of the training drug (Quertemont, 2003). Importantly, research with this discriminated taste aversion preparation has confirmed many of the findings from the operant drug discrimination literature (eg Quertemont, 2003).

Recent experiments from our laboratory have also used drug states to set the occasion for pairings between stimuli (Palmatier et al, 2004; Sanderson et al, 2003). In that research, we used nicotine $(0.4 \mathrm{mg} / \mathrm{kg})$ to signal when a light cue (conditional stimulus or CS) would be followed by brief access to sucrose (unconditional stimulus or US). Nicotine was referred to as a positive 'drug feature' because the drug state provided information about when the CS would be followed by sucrose. To measure the effects of pairing the light CS and sucrose US, we took advantage of rats' tendency to goal track, or approach a place where they had received sucrose in the past (Boakes, 1977; Farwell and Ayres, 1979). Notably, goal-tracking behavior occurred most frequently when the light CS was presented in the nicotine state. Arguably, any drug with perceptible stimulus effects could set the occasion for pairings between an environmental stimulus and a rewarding outcome (ie serve as a positive drug feature).

One goal of the present research was to test the generality of circumstances in which drug states could serve as positive features for CS-sucrose pairings. To do so, we replicated our previous research with nicotine and extended that research to another psychomotor stimulant - amphetamine. Further, to insure that the ability of a drug state to serve as a positive feature for a CS-US association was not limited to stimulants, we also examined whether the anxiolytic chlordiazepoxide (CDP) could serve as a drug feature. A final goal of this research was to examine the pharmacological profile of amphetamine, nicotine, and CDP within the present paradigm. As mentioned previously, paradigms that generate pharmacologically specific behaviors allow researchers to explore the neuropharmacological properties of various drug states. Therefore, we further examined the cueing properties of the drug features with various stimulus substitution tests. 'Pharmacological specificity' suggests that the pharmacological effects of the drug state set the occasion for the goal-tracking conditional response (CR). Accordingly, specificity should be evidenced by attenuation of the $\mathrm{CR}$ as the result of changes in dose or substitution of other compounds.

\section{MATERIALS AND METHODS}

\section{Subjects}

A total of 35 male Sprague-Dawley rats were obtained from Harlan (Indianapolis, IN) and housed individually in clear plastic tubs lined with wood shavings in a temperature- and humidity-controlled colony. Rats had free access to water in the home cage; however, access to food was restricted such that rats were maintained at $85 \%$ of their free-feeding weight (mean $=324 \pm 58 \mathrm{~g}$ ). This weight was increased by $2 \mathrm{~g}$ every 28 days to approximate a normal growth curve provided by the supplier. Experimental sessions were conducted on consecutive days during the light portion of a $12 \mathrm{~h}$ light: dark cycle. All procedures were approved by the University of Nebraska-Lincoln IACUC and followed the 'Principles of laboratory animal care' (NIH publication no. 85-23, revised 1985).

\section{Apparatus}

Experiments were conducted in seven standard operant conditioning chambers (ENV-008CT; Med Associates, Georgia, VT) each housed in a sound-attenuating cubicle fitted with a fan to provide airflow and masking noise. Each chamber measured $30.5 \times 24.1 \times 21 \mathrm{~cm}(1 \times \mathrm{w} \times \mathrm{h})$; the sidewalls were aluminum and all stimulus elements were attached to these walls. The top and rear walls and the door of the chamber were constructed of clear polycarbonate. One side of each chamber was fitted with a liquid dipper in a receptacle; the dipper had a 0.1-ml cup attached for sucrose delivery. The receptacle was fitted with an infrared emitter/detector unit to monitor head entries. Two white stimulus lights $(100 \mathrm{~mA})$ were mounted above and to either side of the dipper receptacle on the same wall. A white noise speaker and amplifier unit $(70 \mathrm{~dB})$ was mounted to the top of the wall opposite the dipper. Illumination of the lights or initiation of the white noise served as the CS. A personal computer with Med-Associates interface and software controlled the stimulus events and recorded dipper entries throughout each session.

\section{Drugs}

(-)-Nicotine hydrogen tartrate, $d$-amphetamine sulfate, caffeine anhydrous, and chlordiazepoxide hydrochloride (Sigma/RBI, St Louis, MO) were dissolved in physiological saline. Nicotine was brought to a $\mathrm{pH}$ of $7.0 \pm 0.2$ with a dilute $\mathrm{NaOH}$ solution and injected subcutaneously (s.c.) at $1 \mathrm{ml} / \mathrm{kg}$. Amphetamine and CDP were injected intraperitoneally (i.p.) at $1 \mathrm{ml} / \mathrm{kg}$, and caffeine was injected i.p. at $2 \mathrm{ml} / \mathrm{kg}$. Nicotine doses are expressed as the base form. Doses of all other compounds are expressed as the salt form.

\section{Dipper Training}

In the first three 50-min sessions, rats were trained to access $26 \%$ sucrose $(\mathrm{w} / \mathrm{v})$ within $4 \mathrm{~s}$, regardless of their location in the chamber. Sucrose was delivered according to a probability function, which decreased from 0.167 to 0.05 per $4 \mathrm{~s}$ (approximately $2.5-0.75$ sucrose deliveries per minute) 
over the three sessions. Robust dipper-entry behavior was evident for all rats by the end of this phase.

\section{Discrimination Training}

Following dipper training, all rats underwent discrimination training. The training phase was separated into 8-day cycles during which each rat received four drug and four saline sessions in a quasirandom order. The cycles were constructed such that the same session type (drug or saline) did not occur on more than 2 consecutive days. Each session was controlled by one of four Med-State Notation programs. The programs differed with regard to first trial onset (mean $=120 \mathrm{~s}$, range $=90-150 \mathrm{~s})$ and order of inter-trial intervals (ITIs, CS offset to next CS onset). For each program, ITIs were randomly chosen from a distribution $($ mean $=154 \mathrm{~s}$, range $=94-214 \mathrm{~s})$, with each ITI occurring no more than twice in a session. Across an 8-day cycle, each program controlled one drug session and one saline session. There were eight presentations of the 15-s CS (white noise or light) during each session. On drug sessions, the CS was followed immediately by 4 -s access to sucrose. On saline sessions, the CS was followed by a 4-s empty interval. Minor variations in training procedures across drug features are outlined in the following sections.

Nicotine. Rats in this condition $(n=14)$ received nicotine $(0.4 \mathrm{mg} / \mathrm{kg})$ or saline injections $5 \mathrm{~min}$ before the start of each experimental session. CS modality (light or white noise) was counterbalanced within this condition.

Amphetamine. Rats in this condition $(n=14)$ received amphetamine $(1 \mathrm{mg} / \mathrm{kg})$ or saline injections $15 \mathrm{~min}$ before the start of each experimental session. CS modality (light or white noise) was counterbalanced within this condition.

$C D P$. Originally, an experimental goal for this condition was to assess potential state-dependent effects of CDP. As a result, these rats $(n=7)$ started with 16 consecutive drug sessions following dipper training. CDP $(5 \mathrm{mg} / \mathrm{kg})$ was injected $15 \mathrm{~min}$ before the start of each session and all CS presentations were followed by 4-s access to sucrose. On the 17th training session, all rats received a saline injection $15 \mathrm{~min}$ before the start of the session. This session served as a test for state-dependent learning (Wilkinson et al, 2003) and the first session of intermixed drug and saline cycles (ie discrimination training; see Palmatier et al (2004) for analogous procedures with $0.4 \mathrm{mg} / \mathrm{kg}$ nicotine). All CDP rats were trained with the light CS due to criterion failures with the white noise (see later).

\section{Substitution Tests}

After discrimination training, rats were tested with varying doses of the training drug and other pharmacological compounds. During testing, cycles were shifted from 8 to 7 days. This 7-day cycle was composed of six training sessions and one test session. Days 3-6 of each testing cycle included two drug sessions and two saline sessions; data from these sessions were used to assess the performance criteria across test cycles (see later). Rats not meeting criteria remained in the home cage for the test session. Test sessions were controlled by modified versions of saline training session programs. Thus, CS onset varied between test sessions and no sucrose was delivered. The test sessions included only one CS presentation and terminated after 4 min. Substitution tests were conducted in three phases. Phase I tested various doses of the training drug (ie generalization tests). Phase II included substitution tests that examined various doses of the other training drugs. Phase III tested caffeine's ability to substitute for each training drug. For all phases, rats were tested with each dose in one random order, and then each dose was tested again in a different random order. For the nicotine and amphetamine conditions, data were collected in two replications $(n=7$ per drug per replication). We found no differences in acquisition across replications, $\mathrm{F}(1,12) \leqslant 1.39, p \geqslant 0.26$; however, only rats from the first replication continued to Phase III (caffeine). All rats in the CDP condition completed the three test phases.

\section{Dependent Measure}

The number of dipper entries was recorded in 15-s intervals. Elevation scores were calculated by subtracting the number of dipper entries that occurred in the $15 \mathrm{~s}$ before CS onset (pre-CS) from dipper entries that occurred during the 15-s CS (CS minus pre-CS; cf Brooks and Bouton, 1994). Average elevation scores for each session served as the main dependent measure. An elevation score of 0 indicates equal goal tracking during the CS and pre-CS periods across a session; a positive elevation score indicates more goal tracking during the CS. Dipper entries (ie goal tracking) were also recorded during each $4 \mathrm{~s}$ sucrose delivery; however, these entries were not included in any dependent measure.

\section{Performance Criteria}

Prior to substitution tests, each rat was required to meet two conditions. First, mean elevation scores for saline sessions were subtracted from mean elevation scores for corresponding drug sessions; testable performance was defined as a mean difference score $\geqslant 3$. Second, a similar contrast was conducted on first trial elevation scores for the last drug and saline training sessions of each cycle except that difference scores had to be $\geqslant 1$. These performance criteria were chosen a priori based on previous experiments from our laboratory.

For rats in the nicotine and amphetamine conditions, initial performance criteria were assessed after seven training cycles (56 sessions). In the nicotine condition, two rats trained with the white noise CS did not meet the criteria. In the amphetamine condition, three rats (two white noise, one light) did not meet criteria. These rats were dropped from the experiment and their data excluded from analyses. For rats in the CDP condition, two intermixed drug and saline cycles were conducted before criteria performance was assessed (32 total training sessions). All rats met criteria. 


\section{Data Analyses}

For the discrimination training phase, average elevation scores were analyzed with one- or two-way analyses of variance (ANOVAs) where appropriate. Significant interactions were explored with paired sample $t$-tests. For substitution tests with the training drug, one-way repeated measures ANOVA examined average elevation scores for each dose included in the randomized test blocks. For the generalization tests (ie training drug), significant ANOVAs were followed up by contrasts between the training dose and remaining test doses. Conditions that differed from the training dose were subsequently compared to a 'no-drug' control condition (see later). For CDP rats, two controls were included in the test blocks (ie training dose and saline). Accordingly, Bonferroni's multiple-comparisons test contrasted each control condition with the remaining test conditions. Substitution tests with nontraining drugs (ie Phases II and III) did not include these comparison conditions in the randomized test blocks. Thus, comparison data were taken from the first trial of drug and saline training sessions that preceded one of the test doses from each phase. Significant ANOVAs prompted contrasts comparing the no-drug control to each test dose. Doses that differed from this no-drug control were subsequently compared to the training drug control. Linear regression on doses from the ascending limb of the dose effect curve was used to calculate a median effective dose $\left(E D_{50}\right)$ when full substitution was observed.

\section{RESULTS}

\section{Discrimination Training}

Nicotine. Average elevation scores from the training phase are presented in Figure 1a. The two-way ANOVA revealed significant main effects of Drug (nicotine $v s$ saline), $\mathrm{F}(1,297)=121.25, p<0.001$, and Session, $\mathrm{F}(27,297)=6.67$, $p<0.001$, as well as a significant Drug $\times$ Session interaction, $\mathrm{F}(27,297)=8.24, p<0.001$. Scores from nicotine sessions were significantly higher than saline from sessions 4 to 28 $($ smallest $t(11)=4.66, p<0.01($ Session 4$))$.

Amphetamine. Average elevation scores from the training phase are presented in Figure 1b. The two-way ANOVA revealed significant main effects of Drug (amphetamine vs saline), $\mathrm{F}(1,270)=25.67, p<0.001$, and Session, $\mathrm{F}(27,270)=$ $3.55, \quad p<0.01$, as well as a significant Drug $\times$ Session interaction, $\mathrm{F}(27,270)=3.22, p<0.01$. Mean elevation scores from amphetamine sessions were significantly higher than saline from sessions 3 to 28 (smallest $t(10)=2.52, p=0.03$ (Session 8)).

$C D P$. Average elevation scores from the training phase are presented in Figure 1c. The one-way ANOVA conducted on elevation scores from the first 16 CDP sessions revealed a significant main effect of Session, $\mathrm{F}(15,90)=11.98, p<0.01$. The two-way ANOVA on the subsequent 16 intermixed sessions revealed a significant main effect of Drug (CDP vs saline), $\mathrm{F}(1,42)=22.79, p<0.01$. The main effects of Session and the Drug $\times$ Session interaction were not significant, $\mathrm{F}(7,42) \leqslant 1.80, p \geqslant 0.11$.
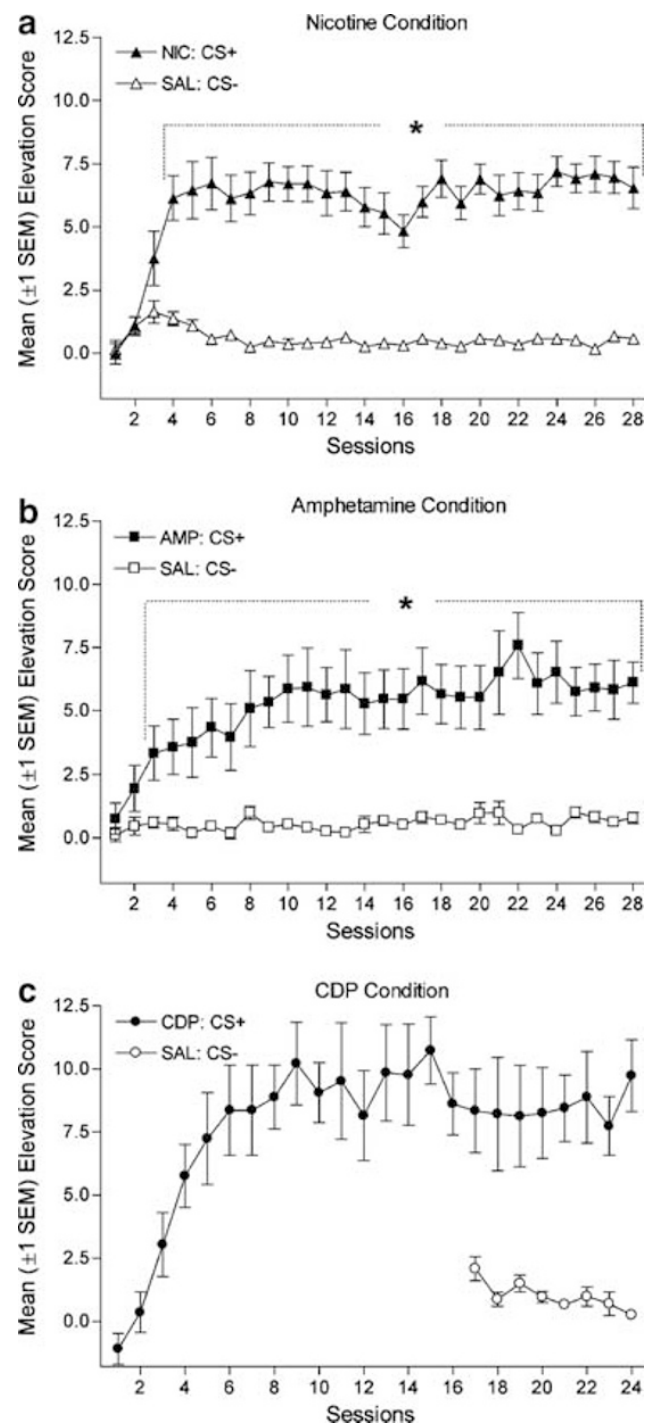

Figure I Panels (a) and (b) illustrate mean elevation scores ( \pm I SEM) across discriminatory training sessions for rats in the nicotine and amphetamine conditions, respectively. Rats received injections of drug or saline $5 \mathrm{~min}$ (nicotine condition) or $15 \mathrm{~min}$ (amphetamine condition) prior to training sessions (Sessions 1-28). On sessions preceded by drug injection, $15 \mathrm{~s}$ presentations of a CS were followed immediately by $4 \mathrm{~s}$ access to sucrose (US). On saline sessions, the same CS was followed by a 4 s empty interval. Drug and saline sessions occurred on separate days, but are overlaid in order of occurrence to facilitate comparison. Panel c illustrates mean elevation scores ( \pm I SEM) across training sessions for rats in the CDP condition. For CDP rats, the training phase began with 16 consecutive drug sessions during which the CS was always followed by sucrose. Two intermixed drug and saline cycles ( 16 total sessions) began on Session 17; all other parameters were similar to the amphetamine condition. * indicates that mean elevation score on drug session differs significantly from comparable saline session, $p<0.05$.

Dipper entries. The elevation score, our primary dependent measure, reflects a difference between dipper entries during the CS relative to an equivalent time just before the CS (ie pre-CS period). Of interest is the absolute number of dipper entries and whether these entries during this pre-CS period differ between saline and drug state. This latter comparison provides a measure of the nonspecific and/or rate-altering effects of the drug feature. Accordingly, the pre-CS and CS 
dipper entries from the last drug and saline sessions before testing are presented in Table 1 . Paired $t$-tests contrasted dipper entries during the pre-CS intervals across drug states to examine the potential rate-altering effects of nicotine, amphetamine, and CDP. Dipper entries during the pre-CS periods did not differ for the nicotine or CDP trained rats, $t<1$. Because of the lower levels of dipper entries during the saline session, there was a nonsignificant trend for more dipper entries during the pre-CS period on amphetamine sessions relative to saline sessions, $t(10)=2.06, p=0.07$. These results indicate that training drug did not have a significant effect on baseline levels of dipper entries. Regardless, the elevation score controls for any potential baseline differences such that differences in elevation score between saline and drug session reflect drug state-specific goal tracking to the CS (ie conditioned responding).

\section{Substitution Tests}

Nicotine. Mean elevation scores from the nicotine substitution tests (Phase I) are presented in the left half of Figure 2. There was a significant main effect of Dose, $F(6,83)=4.12$, $p<0.001$. Dunnett's multiple-comparisons test indicated

Table I Mean Dipper Entries (SEM) Occurring during the $15 \mathrm{~s}$ Prior to CS Onset (pre-CS) and during the 15-s CS on the Last Drug and Saline Sessions of Discrimination Training

\begin{tabular}{llcc}
\hline $\begin{array}{l}\text { Training } \\
\text { drug }\end{array}$ & $\begin{array}{l}\text { Session } \\
\text { type }\end{array}$ & $\begin{array}{c}\text { Pre-CS dipper } \\
\text { entries }\end{array}$ & $\begin{array}{c}\text { CS dipper } \\
\text { entries }\end{array}$ \\
\hline Nicotine & Drug & $1.25(0.24)$ & $7.82(0.75)$ \\
& Saline & $0.94(0.24)$ & $1.43(0.43)$ \\
Amphetamine & Drug & $0.99(0.21)$ & $7.10(0.86)$ \\
& Saline & $0.64(0.13)$ & $1.43(0.49)$ \\
CDP & Drug & $0.91(0.37)$ & $9.88(1.27)$ \\
& Saline & $0.84(0.30)$ & $1.57(0.47)$ \\
\hline
\end{tabular}

CDP: chlordiazepoxide. that elevation scores from the three lowest nicotine test doses $(0.01,0.03$, and $0.05 \mathrm{mg} / \mathrm{kg})$ were significantly lower than the training dose $(0.4 \mathrm{mg} / \mathrm{kg}), p<0.01$. Elevation scores from the 0.03 and $0.05 \mathrm{mg} / \mathrm{kg}$ tests also differed from saline controls (smallest $t(11)=4.24, p<0.01(0.03 \mathrm{mg} / \mathrm{kg})$ ). The $\mathrm{ED}_{50}$ from the ascending limb of the dose-effect curve $(0.01-0.1 \mathrm{mg} / \mathrm{kg})$ was $0.054 \mathrm{mg} / \mathrm{kg}$.

Mean elevation scores from the CDP, amphetamine, and caffeine substitution tests (Phases II and III) are presented in the right half of Figure 2. The one-way ANOVA on CDP data was not significant, $\mathrm{F}<1$. For amphetamine tests, the one-way ANOVA revealed a significant main effect of Dose, $\mathrm{F}(3,47)=3.36, p<0.001$. However, none of the elevation scores from amphetamine tests differed from saline controls, $t(11) \leqslant 1.88, p \geqslant 0.09$. For caffeine, the one-way ANOVA revealed a significant main effect of Dose, $\mathrm{F}(3,27)=15.35, p<0.001$. Elevation scores from the 10 and $30 \mathrm{mg} / \mathrm{kg}$ caffeine tests significantly differed from saline controls, $t(6) \geqslant 3.37, p \leqslant 0.02$. This difference from saline controls prompted further contrasts with nicotine control data to examine whether these caffeine doses fully substituted for the nicotine feature. Elevation scores from the $10 \mathrm{mg} / \mathrm{kg}$ test differed from nicotine controls, $p=0.013$; however, elevation scores from the $30 \mathrm{mg} / \mathrm{kg}$ test did not differ significantly from this control condition, $p=0.08$. The $\mathrm{ED}_{50}$ from the ascending limb of the caffeine dose-effect curve $(2.5-30 \mathrm{mg} / \mathrm{kg})$ was $15.45 \mathrm{mg} / \mathrm{kg}$.

Amphetamine. Mean elevation scores from the amphetamine substitution tests are presented in the left half of Figure 3. One-way ANOVA revealed a significant main effect of Dose, $\mathrm{F}(6,76)=4.82, p<0.001$. Dunnett's multiplecomparisons test indicated that elevation scores from the two lowest amphetamine doses $(0.0625$ and $0.125 \mathrm{mg} / \mathrm{kg})$ were significantly lower than the training dose $(1.0 \mathrm{mg} / \mathrm{kg})$, $p<0.01$. Elevation scores from the $0.125 \mathrm{mg} / \mathrm{kg}$ test also differed significantly from saline controls, $t(10)=2.27$, $p=0.047$. The $\mathrm{ED}_{50}$ from the ascending limb of amphetamine dose-effect function $(0.0625-0.5 \mathrm{mg} / \mathrm{kg}$ conditions) was $0.281 \mathrm{mg} / \mathrm{kg}$.
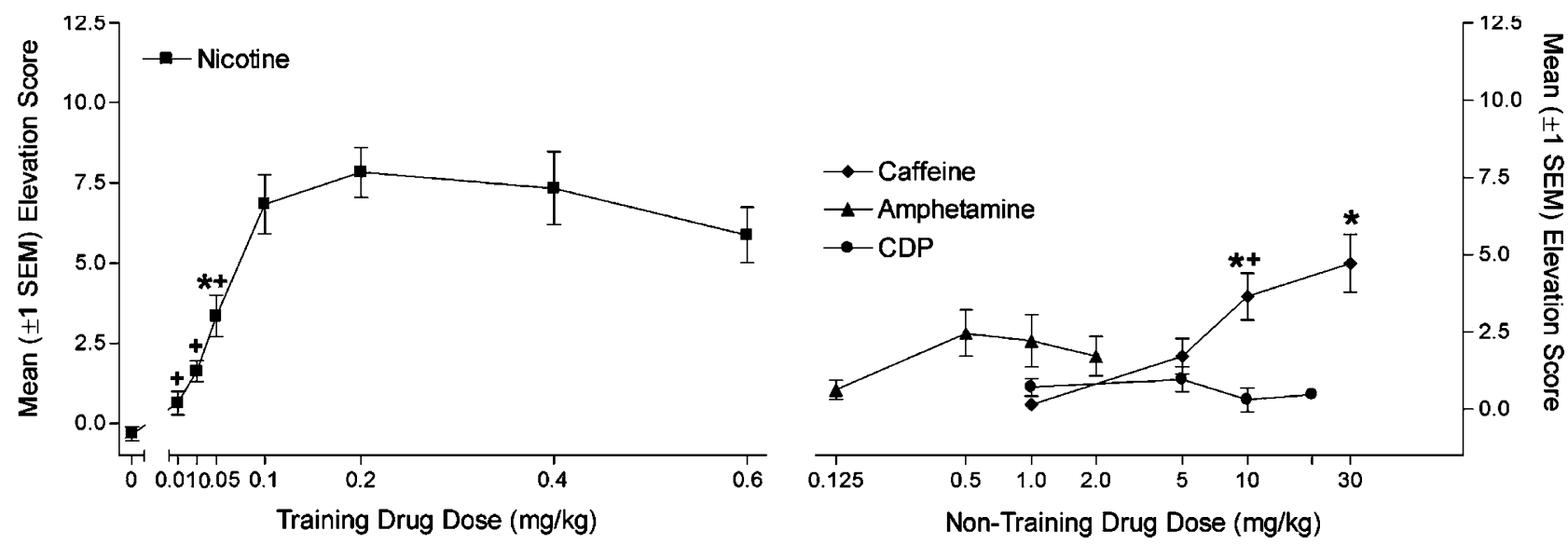

Figure 2 Illustration of mean elevation scores ( \pm I SEM) from the substitution tests for rats in the nicotine condition. The left half of the figure illustrates substitution tests with the training drug (ie generalization tests). The right half of the figure illustrates substitution tests with nontraining drugs. * indicates that mean elevation score differs significantly from saline control, $p<0.05$. + indicates that mean elevation score differs significantly from training drug control, $p<0.05$. 

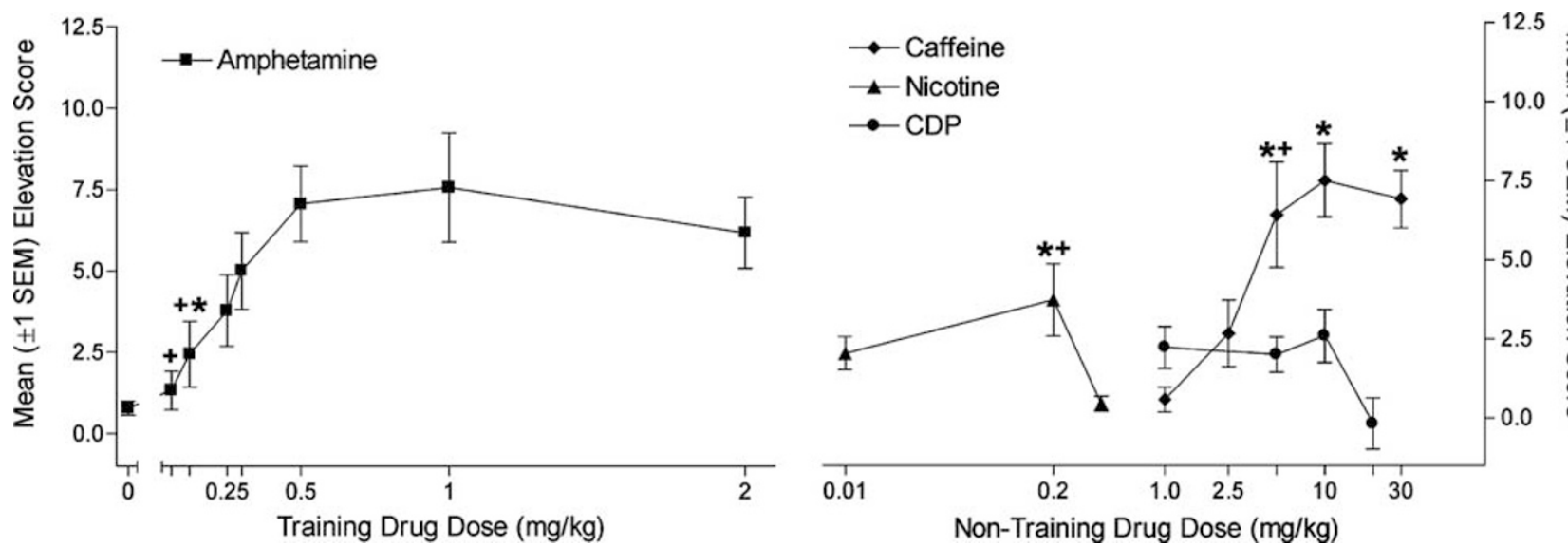

Figure 3 Illustration of mean elevation scores ( \pm I SEM) from the substitution tests for rats in the amphetamine condition. The left half of the figure illustrates substitution tests with the training drug (ie generalization tests). The right half of the figure illustrates substitution tests with nontraining drugs. * indicates that mean elevation score differs significantly from saline control, $p<0.05$. + indicates that mean elevation score differs significantly from training drug control, $p<0.05$.
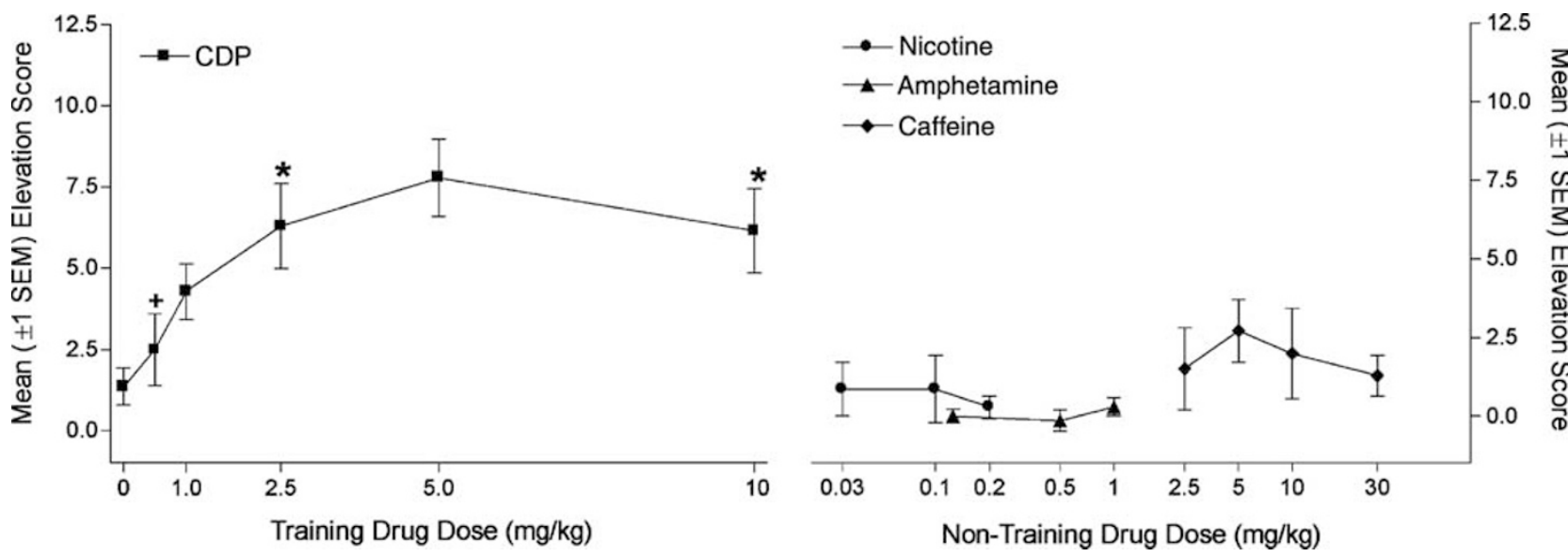

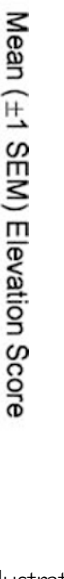

Figure 4 Illustration of mean elevation scores ( \pm I SEM) from the substitution tests for rats in the CDP condition. The left half of the figure illustrates substitution tests with the training drug (ie generalization tests). The right half of the figure illustrates substitution tests with nontraining drugs. $*$ indicates that mean elevation score differs significantly from saline control, $p<0.05$. + indicates that mean elevation score differs significantly from training drug control, $p<0.05$.

Mean elevation scores from the CDP, nicotine, and caffeine substitution tests are presented in the right panel of Figure 3. The one-way ANOVA for CDP data was not significant, $\mathrm{F}(4,54)=2.56, p=0.053$. For nicotine tests, the one-way ANOVA revealed a significant main effect of Dose, $\mathrm{F}(3,43)=4.48, p=0.02$. Elevation scores from the $0.2 \mathrm{mg} / \mathrm{kg}$ nicotine dose differed from saline controls, $t(10)=2.36$, $p=0.04$, and the amphetamine training dose, $t(10)=5.23$, $p<0.001$. For caffeine tests, the one-way ANOVA revealed a significant main effect of Dose, $\mathrm{F}(4,29)=11.77, p<0.001$. Subsequent comparisons revealed that the 5,10 , and $30 \mathrm{mg} /$ $\mathrm{kg}$ caffeine doses differed from saline controls, $t(5) \geqslant 3.18$, $p \leqslant 0.024$. Elevation scores from the $5 \mathrm{mg} / \mathrm{kg}$ condition also differed from the amphetamine training dose, $t(5)=4.91$, $p<0.01$; however, the 10 and $30 \mathrm{mg} / \mathrm{kg}$ doses did not differ from this amphetamine control, $t(5) \leqslant 2.24, p \geqslant 0.08$. The $\mathrm{ED}_{50}$ from the ascending limb of the caffeine dose-effect curve $(1-10 \mathrm{mg} / \mathrm{kg})$ was $3.70 \mathrm{mg} / \mathrm{kg}$.
CDP. Mean elevation scores from CDP substitution tests are presented in the left half of Figure 4. For this group, a saline control condition was included in the test blocks and is therefore included in overall analyses and follow-ups. The one-way ANOVA revealed a significant main effect of Dose, $\mathrm{F}(5,41)=3.83, p<0.01$. Bonferroni's multiple-comparisons tests indicated that elevation scores from 2.5 and $10 \mathrm{mg} / \mathrm{kg}$ conditions differed significantly from the saline control, $p<0.05$, but not from the $5 \mathrm{mg} / \mathrm{kg}$ CDP training dose, $p>0.05$. The $0.5 \mathrm{mg} / \mathrm{kg}$ dose differed significantly from the training dose, $p<0.05$, but not from saline, $p>0.05$. The $\mathrm{ED}_{50}$ from the ascending limb of the CDP dose-effect curve $(0-5 \mathrm{mg} / \mathrm{kg})$ was $2.48 \mathrm{mg} / \mathrm{kg}$. Mean elevation scores from the nicotine, amphetamine, and caffeine substitution tests are presented in the right half of Figure 4. One-way ANOVAs conducted separately on nicotine, amphetamine, and caffeine test conditions were not significant, $\mathrm{F} \leqslant 1.20$, $p \geqslant 0.33$. 


\section{DISCUSSION}

In the present studies, nicotine, amphetamine, and CDP drug states indicated when a discrete exteroceptive CS would be followed by a reward (ie access to sucrose). This training resulted in a drug state-specific goal-tracking CR. These studies extend our previous findings with nicotine (Palmatier et al, 2004; Sanderson et al, 2003) to other drug states (amphetamine and CDP) and to an auditory CS (white noise). Importantly, we also found that the CR was pharmacologically specific; changes in the salience (ie dose) and pharmacological properties (ie compound) of the drugs decreased CS-specific goal tracking. Notably, some doses of caffeine (eg $30 \mathrm{mg} / \mathrm{kg}$ ) occasioned conditional responding at a magnitude similar to nicotine (Figure 2) and amphetamine (Figure 3).

The finding that a drug state-specific CR was controlled by amphetamine extends our previous research with nicotine (Palmatier et al, 2004; Sanderson et al, 2003) to another psychomotor stimulant that has some distinct pharmacological actions in the central nervous system (Bardo et al, 1997). This generality is further extended by the finding that the anxiolytic CDP readily serves as a drug feature that signals a CS-US association. Thus, $5 \mathrm{mg} / \mathrm{kg} \mathrm{CDP}$, which typically has some motor impairing effects (Angrini et al, 1998), can prompt an excitatory CR (ie goal tracking) to a discrete CS. One alternative explanation to a drug statespecific CR is that the psychomotor stimulant effects of the drug features prompted increased goal tracking during drug sessions. Although this possibility applies less to CDP than to nicotine and amphetamine (Angrini et al, 1998; Palmatier et al, 2003), the elevation score was employed to control for this possibility. The dipper entry data presented in Table 1 indicate that the training doses of each drug feature did not significantly increase dipper entries during the pre-CS. Further, there is no parsimonious a priori reason to expect the nonspecific motor effects of the drug features to differentially affect dipper entries more during CS intervals relative to pre-CS intervals - particularly to the magnitude found in the present experiments. The magnitude of increase during the drug feature to the CS was 5- to 6.5fold over that of saline (see Table 1). Most notably, the largest increase was seen with CDP and not the more potent psychomotor stimulants.

Related to this discussion is the possibility that the change in physiological states between drug and saline sessions prevented recall of the CS-US association and/or performance of the $\mathrm{CR}$ in the saline state (ie statedependent learning; Cunningham, 1979). Although we cannot explicitly rule out these processes in the present experiments, preliminary tests for state-dependent learning using procedures similar to those of the CDP group (eg Palmatier et al, 2004; Wilkinson et al, 2003) decrease our enthusiasm for this interpretation. In those studies, repeated pairing of the CS and sucrose in the drug state results in anticipatory sucrose seeking during the CS (ie positive elevation scores; Figure 1c). Following acquisition of this CR, the CS was presented in the saline state for the first time. Notably, responding to the first CS presentation in the saline state did not differ from responding during the preceding session in the drug state. Thus, the CR was not disrupted by a change in physiological conditions. Further studies will be required to examine whether the converse state change (ie saline to drug) or further training can establish state dependency.

A second important finding of the present research was that an auditory cue (white noise) also served as the discrete CS in a drug occasioned goal-tracking discrimination. Previous research had established that nicotine could set the occasion for goal tracking to a visual CS (Palmatier $e t a l$, 2004). Interestingly, rats trained with the white noise CS were less likely to meet performance criteria than rats trained with the light CS (71 vs 93\%, respectively). One potential reason for this difference is that the white noise is a less salient cue than the light. Such a discrepancy could yield a weaker association between the white noise and sucrose relative to the association between the light and sucrose (eg Mackintosh, 1971; Rescorla and Wagner, 1972). However, detailed examination of the data decreases our enthusiasm for this account. Four rats trained with the white noise CS failed to meet the performance criteria. Of these, three rats would have met criteria if it were assessed earlier in discrimination training. For these rats, the goaltracking CR weakened with continued training. This postasymptotic decrement has been previously reported with auditory conditional stimuli and has been attributed to a 'maintained headpoke' CR (Carrigan et al, 1972; Farwell and Ayres, 1979). For example, Farwell and Ayres (1979) noted that ' ... rats with the light CS periodically pulled their heads out of the dipper receptacle during CSs, as if to see if the light were still on. Each time this 'checking' behavior occurred, a response was recorded. This tendency was not noted for rats with auditory CSs' ( $p$ 300). Recent experiments in our laboratory have confirmed that the maintained headpoke CR is readily expressed when rats are trained with the white noise CS. This topography is further exacerbated by the presence of nonstimulant drugs such as CDP (Palmatier, 2004).

The third finding of major interest from these studies is the pattern of stimulus substitution. The results of these tests were generally consistent with previous operant conditioning studies and suggest the potential utility of this Pavlovian appetitive conditioning preparation in assessing the behavioral and neuropharmacological processes mediating the subjective effects of drugs. For example, the $\mathrm{ED}_{50}$ for nicotine $(0.054 \mathrm{mg} / \mathrm{kg})$ was in the lower end of the range described for operant conditioning experiments using a $0.4 \mathrm{mg} / \mathrm{kg}$ training dose $(0.05 \mathrm{mg} / \mathrm{kg}$ (Gasior et al, 1999), $0.087 \mathrm{mg} / \mathrm{kg}$ (Chance et al, 1977), and $0.14 \mathrm{mg} / \mathrm{kg}$ (Pratt et al, 1983)). The $\mathrm{ED}_{50}$ for amphetamine $(0.281 \mathrm{mg} / \mathrm{kg})$ was also within the range described in operant drug discrimination experiments employing a $1 \mathrm{mg} / \mathrm{kg}$ training dose $(0.26 \mathrm{mg} / \mathrm{kg}$ (Bevins et al, 1997) and $0.40 \mathrm{mg} / \mathrm{kg}$ (Young et al, 1998)]. Also similar to previous findings using operant drug discrimination procedures, CDP did not substitute for any of the stimulants that we trained as drug features (eg Stolerman et al, 1984), nor did any stimulant substitute for CDP (eg Gauvin et al, 1994). Finally, nicotine and amphetamine partially substituted for one another, although only $0.2 \mathrm{mg} / \mathrm{kg}$ nicotine statistically differed from saline controls (for similar findings in operant drug discrimination studies, see Bardo et al, 1997; Chance et al, 1977; Li and McMillan, 2003; Mansbach et al, 1998; Stolerman, 1989). 
Two findings from the present substitution tests require further discussion. First, the $\mathrm{ED}_{50}$ for $\mathrm{CDP}(2.5 \mathrm{mg} / \mathrm{kg})$ was higher than previous operant drug discrimination studies using the same training dose $(1.5 \mathrm{mg} / \mathrm{kg}$ (Schechter and Lovano, 1985) and $1.83 \mathrm{mg} / \mathrm{kg}$ (De Vry and Slangen, 1986)). Although this difference seems marginal, it is higher than $\mathrm{ED}_{50} \mathrm{~s}$ reported in operant conditioning studies, whereas $\mathrm{ED}_{50} \mathrm{~s}$ for the nicotine and amphetamine features were on the lower end of the distribution reported in the operant drug discrimination literature. One possibility is that the different training procedures employed for CDP $v s$ nicotine and amphetamine resulted in differences in sensitivity to the drug stimuli and subsequently, different median effective doses. A more comprehensive analysis of the occasion setting properties of CDP, including training procedures and CR topography (see earlier), should be conducted before any conclusions are made about this difference.

Second, caffeine dose-dependently substituted for nicotine and amphetamine $\left(\mathrm{ED}_{50} \mathrm{~s} 15.45\right.$ and $3.7 \mathrm{mg} / \mathrm{kg}$, respectively); complete substitution was evident at the highest caffeine doses (eg $30 \mathrm{mg} / \mathrm{kg}$ ). At first glance, the pattern of substitution by caffeine appears to reflect nonspecific generalization within a pharmacological class (ie stimulants). However, this conclusion is not supported by the pattern of substitution between nicotine and amphetamine, which was partial and only statistically reliable when $0.2 \mathrm{mg} /$ $\mathrm{kg}$ nicotine was tested in rats trained with $1 \mathrm{mg} / \mathrm{kg}$ amphetamine. Also, the median effective dose for caffeine was much higher when it was substituted for the nicotine feature, relative to the amphetamine feature, suggesting that substitution by caffeine is more potent for rats trained with amphetamine. There is mixed evidence in operant drug discrimination research that caffeine can substitute for nicotine and amphetamine. For example, caffeine does not substitute for $1 \mathrm{mg} / \mathrm{kg}$ amphetamine in pigeons ( $\mathrm{Li}$ and McMillan, 2003). In humans, caffeine $(300 \mathrm{mg})$ partially substitutes (60\% drug-appropriate responding) for the stimulus effects of amphetamine $(10 \mathrm{mg}$; Chait and Johanson, 1988). In rats, some researchers have found that caffeine fully substitutes for $1 \mathrm{mg} / \mathrm{kg}$ amphetamine (Young et al, 1998), whereas others found only partial substitution (Clark et al, 1995). Notably, we found caffeine substitution at much lower doses than that reported by Young and colleagues (1998) despite using an identical amphetamine training dose $(1 \mathrm{mg} / \mathrm{kg})$. In that study, the $\mathrm{ED}_{50}$ for caffeine was $12.9 \mathrm{mg} / \mathrm{kg}$, whereas in the present experiments the $\mathrm{ED}_{50}$ for caffeine was $3.7 \mathrm{mg} / \mathrm{kg}$. Remarkably, a similar dose to the $\mathrm{ED}_{50}$ from the present experiments $(3 \mathrm{mg} / \mathrm{kg})$ evoked $0 \%$ drug-appropriate responding in that study. Moreover, a dose below the $\mathrm{ED}_{50}$ of caffeine in the operant study $(10 \mathrm{mg} /$ $\mathrm{kg}$; Young et al, 1998) evoked $100 \%$ amphetamine-appropriate responding in the present study. Caffeine does not substitute for $0.4 \mathrm{mg} / \mathrm{kg}$ nicotine in rats (Gasior et al, 2002; Rosecrans, 1989). However, caffeine partially substitutes for a low dose of nicotine $(1 \mathrm{mg})$ delivered to humans in chewing gum (Duka et al, 1998). Imaginably, the profile of substitution for caffeine, or any of the compounds tested, could be influenced by the training dose of the drug features. An important matter for future studies will be to investigate how the training dose of the drug features affects the profile of generalization and substitution by other compounds.
Regardless, the substitution by caffeine for both the nicotine and amphetamine features in the present studies suggests that similar mechanisms are responsible for their cueing effects. There is considerable empirical evidence for such similarities in drug discrimination and in other behavioral paradigms. For example, caffeine pre-exposure and/or coadministration enhances the discriminative stimulus effects (ie shifts the dose-effect curve to the left) of nicotine (Gasior et al, 2000, 2002) and amphetamine (Schechter, 1977). Also, caffeine pre-exposure can enhance the psychomotor stimulant effects of nicotine and amphetamine in rats (Gasior et al, 2000; Palmatier et al, 2003). Caffeine also enhances the reinforcing effects of nicotine in rats (Shoaib et al, 1999; Tanda and Goldberg, 2000) and the reinforcing and subjective stimulant effects of intravenous nicotine in humans (Jones and Griffiths, 2003). Notably, amphetamine-induced hyperactivity is also dose-dependently attenuated by pretreatment with selective adenosine $\mathrm{A}_{1}$ and $\mathrm{A}_{2 \mathrm{~A}}$ agonists (Turgeon et al, 1996). Conceivably, whatever pharmacological processes are involved in these interactions could make the subjective effects of caffeine similar to nicotine and amphetamine, even though nicotine and amphetamine were dissimilar in these studies. However, pharmacological similarity alone is not a sufficient explanation when we consider the relative potency of caffeine substitution in the present study, relative to previous operant conditioning studies.

One possible resolution to these discrepancies may be that the Pavlovian procedures employed here do not contain an explicit work requirement. In a two-lever operant drug discrimination procedure, rats typically are shaped to make 10 or more responses on the correct lever before receiving a reward (eg Snodgrass and McMillan, 1991; Stolerman and D'Mello, 1981; also see Liu, 2000). Accordingly, making an incorrect choice results in energy loss and delays the delivery of the next reward. In the present studies, rats must simply approach the goal area (ie dipper receptacle) to receive the reward. However, this response is not schedule-controlled and does not require an explicit choice or the operation of manipulandae. Arguably, the relatively small response cost of a goal-tracking CR might produce a protocol that is more sensitive to overlap in the pharmacological effects that control the stimulus properties of different drugs. These differences will need to be the topic of future research, but the suggestion is consistent with recent evidence that the neurobiological processes involved in Pavlovian and operant conditioning differ (eg Phillips et al, 2003a, b).

Related to this discussion, we have thus far described the procedures and behaviors of interest with terminologies adopted from the Pavlovian conditioning literature. However, we acknowledge that there may be an operant component to goal tracking under adventitious reinforcement by sucrose. After all, the rats are required to approach the goal area in order to receive sucrose access. To date, studies that have attempted to dissociate the roles of operant and Pavlovian processes involved in goal-directed behavior elicited by environmental cues have met with ambiguous results (eg Farwell and Ayres, 1979). Perhaps future studies, such as those investigating Pavlovian to instrumental transfer (eg Holland and Gallagher, 2003), or the importance of unconditional responses (Donahoe and 
Vegas, 2004), will add insights to the similarities and differences between Pavlovian and operant contributions to cue-evoked goal tracking. Regardless, the Pavlovian terminologies are used because the studies were designed and conducted with parameters traditionally employed in the study of Pavlovian appetitive conditioning. Moreover, the behaviors of interest differ in topography from those typically studied in operant conditioning paradigms. Finally, the conditioning procedures employed in the present experiments will allow further exploration of the functional relationships between the cueing properties of drugs and environmental stimuli. For example, drug features that inform pairings between saccharin and lithium can also cue the avoidance of familiar (ie tap water) and novel (ie vinegar) flavor cues (eg Skinner et al, 1998; Skinner, 2000; also see Martin et al, 1990). An important extension of the present work will be to examine whether drug features that cue stimulus-sucrose pairings will transfer their conditional control to other stimuli.

The present experiments offer a preliminary description of a new task for investigating the interactions between drug states and environmental cues. Investigating how drug stimuli set the occasion for conditional 'seeking' behaviors controlled by discrete stimuli might be of particular importance to understanding associative processes involved in compulsive drug use and other compulsive disorders. For example, conditional stimuli evoke 'drug-wanting' responses, which presumably lead to drug seeking and drug taking (Robinson and Berridge, 1993). In recent years, theories of Pavlovian conditioning are placing increased importance on the role of contextual cues (Bouton, 1993, 2002; Kasprow et al, 1987). However, these theories are only just beginning to impact animal models of drug abuse (eg Crombag and Shaham, 2002). Contextual stimuli, interoceptive or exteroceptive, will likely have tremendous impact on the acquisition and expression of 'drug-wanting' CRs or drug seeking. The present paradigm, along with others, will expand our understanding of the functional relationships between contextual stimuli and 'seeking' behavior systems.

\section{ACKNOWLEDGEMENTS}

This research was partially supported by grants from NIH (DA11893) and the UN-L Research Council. The research reported in this paper partially fulfilled the requirements for the doctoral degree of the first author who was supported by NIH Grant DA16179A. We thank Steve Wiltgen for his comments on a previous version of this manuscript and Laura Herrman and Hannah Siebert for their assistance in conducting this research.

\section{REFERENCES}

Angrini M, Leslie JC, Shephard RA (1998). Effects of propranolol, buspirone, pCPA, reserpine, and chlordiazepoxide on open-field behavior. Pharmacol Biochem Behav 59: 387-397.

Bardo MT, Bevins RA, Klebaur JE, Crooks PA, Dwoskin LP (1997). Nornicotine partially substitutes for (+)-amphetamine in a drug discrimination paradigm in rats. Pharmacol Biochem Behav 58: 1083-1087.
Bevins RA, Klebaur JE, Bardo MT (1997). 7-OH-DPAT has d-amphetamine-like discriminative stimulus properties. Pharmacol Biochem Behav 58: 485-490.

Boakes RA (1977). Performance on learning to associate a stimulus with positive reinforcement. In: Davis H, Hurwitz HMB (eds). Operant-Pavlovian Interactions. Lawrence Erlbaum Associates: Hillsdale, NJ. pp 67-101.

Bouton ME (1993). Context, time, and memory retrieval in the interference paradigms of Pavlovian learning. Psychol Bull 114: 80-99.

Bouton ME (2002). Context, ambiguity, and unlearning: sources of relapse after behavioral extinction. Biol Psychiatry 52: 976-986.

Brooks DC, Bouton ME (1994). A retrieval cue for extinction attenuates response recovery (renewal) caused by a return to the conditioning context. J Exp Psychol Anim Behav Process 20: 366-379.

Carrigan PF., Benedict JO, Ayres JJ (1972). A comparison of leverpress and head-poke discriminated Sidman avoidance. Behav Res Methods Instrum 4: 301-303.

Chait LD, Johanson CE (1988). Discriminative stimulus effects of caffeine and benzphetamine in amphetamine-trained volunteers. Psychopharmacology 96: 302-308.

Chance WT, Murfin D, Krynock GM, Rosecrans JA (1977). A description of the nicotine stimulus and tests of its generalization to amphetamine. Psychopharmacology 55: 19-26.

Clark D, Exner M, Furmidge LJ, Svensson K, Sonesson C (1995). Effects of the dopamine autoreceptor antagonist (-)-DS121 on the discriminative stimulus properties of $d$-amphetamine and cocaine. Eur J Pharmacol 275: 67-74.

Colpaert FC (1999). Drug discrimination in neurobiology. Pharmacol Biochem Behav 64: 337-345.

Colpaert FC, Niemegeers CJ, Janssen PA (1976). Theoretical and methodological considerations on drug discrimination learning. Psychopharmacologia 46: 169-177.

Crombag HS, Shaham Y (2002). Renewal of drug seeking by contextual cues after prolonged extinction in rats. Behav Neurosci 116: 169-173.

Cunningham CL (1979). Alcohol as a cue for extinction: state dependency produced by conditioned inhibition. Anim Learn Behav 7: 45-52.

De Vry J, Slangen JL (1986). Effects of training dose on discrimination and cross-generalization of chlordiazepoxide, pentobarbital and ethanol in the rat. Psychopharmacology 88: 341-345.

Donahoe JW, Vegas R (2004). Pavlovian conditioning: The CS-UR relation. J Exp Psychol Anim Behav Process 30: 17-33.

Duka T, Tasker R, Russell K, Stephens DN (1998). Discriminative stimulus properties of nicotine at low doses: the effects of caffeine preload. Behav Pharmacol 9: 219-229.

Farwell BJ, Ayres JJ (1979). Stimulus-reinforcer and response-reinforcer relations in the control of conditioned appetitive headpoking (goal tracking) in rats. Learn Motiv 10: 295-312.

Gasior M, Jaszyna M, Munzar P, Witkin JM, Goldberg SR (2002). Caffeine potentiates the discriminative-stimulus effects of nicotine in rats. Psychopharmacology 162: 385-395.

Gasior M, Jaszyna M, Peters J, Goldberg SR (2000). Changes in the ambulatory activity and discriminative stimulus effects of psychostimulant drugs in rats chronically exposed to caffeine: effect of caffeine dose. J Pharmacol Exp Ther 295: 1101-1111.

Gasior M, Shoaib M, Yasar S, Jaszyna M, Goldberg SR (1999). Acquisition of nicotine discrimination and discriminative stimulus effects of nicotine in rats chronically exposed to caffeine. J Pharmacol Exp Ther 288: 1053-1073.

Gauvin DV, Peirce JM, Holloway FA (1994). Perceptual masking of the chlordiazepoxide discriminative cue by both caffeine and buspirone. Pharmacol Biochem Behav 47: 153-159. 
Herrera FM, Velazquez Martinez DN (1997). Discriminative stimulus properties of amphetamine in a conditioned taste aversion paradigm. Behav Pharmacol 8: 458-464.

Holland PC, Gallagher M (2003). Double dissociation of the effects of lesions of basolateral and central amygdala on conditioned stimulus-potentiated feeding and Pavlovian-instrumental transfer. Eur J Neurosci 17: 1680-1694.

Holtzman SG, Locke KW (1988). Neural mechanisms of drug stimuli: experimental approaches. Psychopharmacol Ser 4: $138-153$.

Jaeger TV, Mucha RF (1990). A taste aversion model of drug discrimination learning: training drug and condition influence rate of learning, sensitivity and drug specificity. Psychopharmacology 100: 145-150.

Jones HE, Griffiths RR (2003). Oral caffeine maintenance potentiates the reinforcing and stimulant subjective effects of intravenous nicotine in cigarette smokers. Psychopharmacology 165: 280-290.

Kasprow WJ, Schachtman TR, Miller RR (1987). The comparator hypothesis of conditioned response generation: manifest conditioned excitation and inhibition as a function of relative excitatory strengths of CS and conditioning context at the time of testing. J Exp Psychol Anim Behav Process 13: 395-406.

Kautz MA, Geter B, McBride SA, Mastropaolo JP, Riley AL (1989). Naloxone as a stimulus for drug discrimination learning. Drug Dev Res 16: 317-326.

Li M, McMillan DE (2003). Retention of sequential drug discriminations under fixed-interval schedules for long time periods without training. Eur J Pharmacol 476: 79-85.

Liu WF (2000). Effects of cholinesterase inhibitors on a twocomponent chained schedule performance in rats. Neurotoxicol Teratol 22: 389-396.

Lucki I (1988). Rapid discrimination of the stimulus properties of 5-hydroxytryptamine agonists using conditioned taste aversion. J Pharmacol Exp Ther 247: 1120-1127.

Mackintosh NJ (1971). An analysis of overshadowing and blocking. Q J Exp Psychol 23: 118-125.

Mansbach RS, Rovetti CC, Freedland CS (1998). The role of monoamine neurotransmitter systems in the nicotine discriminative stimulus. Drug Alcohol Depend 52: 125-134.

Martin GM, Gans M, van der Kooy D (1990). Discriminative properties of morphine that modulate associations between tastes and lithium chloride. J Exp Psychol Anim Behav Process 16: $56-68$.

Mastropaolo JP, Moskowitz KH, Dacanay RJ, Riley AL (1989). Conditioned taste aversions as a behavioral baseline for a drug discrimination learning: an assessment with phencyclidine. Pharmacol Biochem Behav 32: 1-8.

Miyata H, Ando K, Yanagita T (1999). Medial prefrontal cortex is involved in the discriminative stimulus effects of nicotine in rats. Psychopharmacology 145: 234-236.

Palmatier MI (2004). Drug modulators in Pavlovian appetitive conditioning. Dissert Abstr Int 65: 2687.

Palmatier MI, Fung EYK, Bevins RA (2003). Effects of chronic caffeine preexposure on the conditioned and unconditioned psychomotor activity induced by nicotine and amphetamine in rats. Behav Pharmacol 14: 191-198.

Palmatier MI, Peterson JL, Wilkinson JL, Bevins RA (2004). Nicotine serves as a feature-positive modulator of Pavlovian appetitive conditioning in rats. Behav Pharmacol 15: 183-194.

Perkins KA, DiMarco A, Grobe JE, Scierka A, Stiller RL (1994). Nicotine discrimination in male and female smokers. Psychopharmacology 116: 407-413.

Phillips GD, Setzu E, Hitchcott PK (2003a). Facilitation of appetitive pavlovian conditioning by $d$-amphetamine in the shell, but not the core, of the nucleus accumbens. Behav Neurosci 117: 675-684.
Phillips GD, Setzu E, Vugler A, Hitchcott PK (2003b). Immunohistochemical assessment of mesotelencephalic dopamine activity during the acquisition and expression of Pavlovian versus instrumental behaviours. Neuroscience 117: 755-767.

Pratt JA, Stolerman IP, Garcha HS, Giardini V, Feyerabend C (1983). Discriminative stimulus properties of nicotine: further evidence for mediation at a cholinergic receptor. Psychopharmacology 81: 54-60.

Quertemont E (2003). Discriminative stimulus effects of ethanol with a conditioned taste aversion procedure: lack of acetaldehyde substitution. Behav Pharmacol 14: 343-350.

Rescorla RA, Wagner AR (1972). A theory of Pavlovian conditioning: variations in the effectiveness of reinforcement and nonreinforcement. In: Black AH, Prokasy WF (eds). Classical Conditioning II: Current Research and Theory. Appleton-Century-Crofts: New York. pp 64-99.

Revusky S, Coombes S, Pohl RW (1982). Drug states as discriminative stimuli in a flavor-aversion learning experiment. J Comp Physiol Psychol 96: 200-211.

Robinson TE, Berridge KC (1993). The neural basis of drug craving: an incentive-sensitization theory of addiction. Brain Res Rev 18: 247-291.

Rosecrans JA (1989). Nicotine as a discriminative stimulus: a neurobiobehavioral approach to studying central cholinergic mechanisms. J Subst Abuse 1: 287-300.

Sanderson SD, Cheruku SR, Padmanilayam MP, Vennerstrom JL, Thiele GM, Palmatier MI, Bevins RA (2003). Immunization to nicotine with a peptide-based vaccine composed of a conformationally biased agonist of $\mathrm{C} 5 \mathrm{a}$ as a molecular adjuvant. Int Immunopharmacol 3: 137-146.

Schechter MD (1977). Caffeine potentiation of amphetamine: implication for hyperkinesis therapy. Pharmacol Biochem Behav 6: 359-361.

Schechter MD, Lovano DM (1985). Ethanol-chlordiazepoxide interactions in the rat. Pharmacol Biochem Behav 23: 927-930.

Shoaib M, Stolerman IP (1996). Brain sites mediating the discriminative stimulus effects of nicotine in rats. Behav Brain Res 78: 183-188.

Shoaib M, Swanner LS, Yasar S, Goldberg SR (1999). Chronic caffeine exposure potentiates nicotine self-administration in rats. Psychopharamcology 142: 337-343.

Skinner BF (1938). The Behavior of Organisms: An Experimental Analysis. Appleton-Century: England.

Skinner DM (2000). Modulation of taste aversions by a pentobarbital drug state: an assessment of its transfer properties. Learn Motiv 31: 381-401.

Skinner DM, Goddard MJ, Holland PC (1998). What can nontraditional features tell us about conditioning and occasion setting? In: Holland PC, Schmajuk NA (eds). Occasion Setting: Associative Learning and Cognition in Animals. American Psychological Association: Washington, DC. pp 113-144.

Snodgrass SH, McMillan DE (1991). Effects of schedule of reinforcement on a pentobarbital discrimination in rats. $J$ Exp Anal Behav 56: 313-329.

Stolerman IP (1989). Discriminative stimulus effects of nicotine in rats trained under different schedules of reinforcement. Psychopharmacology 97: 131-138.

Stolerman IP, Childs E, Hahn B, Morley A (2002). Drug trace discrimination with nicotine and morphine in rats. Behav Pharmacol 13: 49-58.

Stolerman IP, D’Mello GD (1981). Role of training conditions in discrimination of central nervous system stimulants by rats. Psychopharmacology 73: 295-303.

Stolerman IP, Garcha HS, Pratt JA, Kumar R (1984). Role of training dose in discrimination of nicotine and related compounds by rats. Psychopharmacology 84: 413-419. 
Tanda G, Goldberg SR (2000). Alteration of the behavioral effects of nicotine by chronic caffeine exposure. Pharmacol Biochem Behav 66: 47-64.

Turgeon SM, Pollack AE, Schusheim L, Fink JS (1996). Effects of selective adenosine $\mathrm{A} 1$ and $\mathrm{A} 2 \mathrm{a}$ agonists on amphetamine induced locomotion and c-fos in striatum and nucleus accumbens. Brain Res 707: 75-80.
Wilkinson JL, Palmatier MI, Besheer J, Metschke DM, Bevins RA (2003). A test for state dependent recall of an appetitive association before training a drug state as a feature positive modulator. Neurosci Abstr 33: 941.14.

Young R, Gabryszuk M, Glennon RA (1998). Ephedrine and caffeine mutually potentiate one another's amphetamine-like stimulus effects. Pharmacol Biochem Behav 61: 169-173. 